\title{
Configurações
}

\section{Quando Tudo Se Desmorona: um contributo literário à inter-historicidade}

Things Fall Apart: a literary contribution for inter-historicity

Le Monde s'effondre : une contribution littéraire à l'inter-historicité

\section{Fernanda Costa dos Santos Benedito}

\section{OpenEdition}

\section{Journals}

\section{Edição electrónica}

URL: http://journals.openedition.org/configuracoes/3933

DOI: $10.4000 /$ configuracoes.3933

ISSN: $2182-7419$

\section{Editora}

Centro de Investigação em Ciências Sociais

\section{Edição impressa}

Paginação: 19-33

ISSN: 1646-5075

\section{Refêrencia eletrónica}

Fernanda Costa dos Santos Benedito, « Quando Tudo Se Desmorona: um contributo literário à interhistoricidade », Configurações [Online], 19 | 2017, posto online no dia 30 junho 2017, consultado o 01 maio 2019. URL : http://journals.openedition.org/configuracoes/3933 ; DOI : 10.4000/ configuracoes.3933 
Benedito, Fernanda Costa dos Santos - Quando tudo se desmorona: um contributo literário à inter-historicidade. Configurações, vol. 19, 2017, pp. 19-33

\title{
Quando Tudo Se Desmorona: um contributo literário à inter-historicidade
}

FERNANDA COSTA DOS SANTOS BENEDITO*

Faculdade de Letras da Universidade Agostinho Neto

\begin{abstract}
Resumo
O presente artigo aborda criticamente a obra Quando Tudo Se Desmorona (2008 [1958]), de Chinua Achebe, à luz da reflexão teórico-crítica desenvolvida no quadro dos estudos pós-coloniais e no âmbito da teoria do romance polifónico e carnavalesco de Mikhail Bakhtin, nomeadamente através dos conceitos de contradiscurso, (inter)historicidade, transculturalidade e carnavalização, respetivamente. Pretendemos evidenciar o papel da memória na produção da narrativa das "vozes" silenciadas pela História do recontro colonial e a contribuição dessa narrativa para a (re)afirmação da "autonomia" e do posicionamento da cultura igbo, no quadro da cultura cosmopolita.
\end{abstract}

Palavras-chave: inter-historicidade, contradiscurso, transculturalidade, memória social.

\begin{abstract}
Things Fall Apart: a literary contribution for inter-historicity

This paper critically analyses the novel Things Fall Apart (2008 [1958]), by Chinua Achebe, in light of a post-colonial approach and the theory of the carnivalistic and polyphonic novel of Mikhail Bakhtin, namely through the concepts of counter-discourse, (inter-)historicity, interculturality and carnivalisation, respectively. It is intended to highlight the role of the memory in the production of the narration of "voices" silenced by the history of colonial clash and the contribution of that narration for the (re)affirmation of the "autonomy" of the Igbo culture and its position inside cosmopolitan culture.
\end{abstract}

Keywords: inter-historicity, counter-discourse, transculturality, social memory.

*Centro de Estudos Humanísticos da Universidade do Minho, CEHUM. E-mail: fernandasantos04@ yahoo.com.br 


\section{Résumé}

\section{Le Monde s'effondre : une contribution littéraire à l'inter-historicité}

Cet article analyse de manière critique l'œuvre Le Monde s'effondre (2008 [1958]), de Chinua Achebe, en ayant pour base la réflexion théorico-critique des études postcoloniales et la théorie du roman polyphonique et carnavalesque de Mikhail Bakhtin à travers les concepts de contre-discours, d'(inter-)historicité, de transculturalité et de carnavalisation. L'objectif est de mettre en évidence le rôle de la mémoire dans la production du récit des "voix » mises sous silence par l'Histoire de la confrontation coloniale et la contribution de ce récit à la (ré)affirmation de l' « autonomie » de la culture igbo et de sa place dans la culture cosmopolite.

Mots-clés: inter-historicité, contre-discours, transculturalité, mémoire sociale.

\section{Introdução}

A análise da narrativa de Chinua Achebe que nos propomos fazer não deve, em nosso entender, ser efetuada à margem da história associada ao processo colonial e às suas inerentes tensões e consequências. O simples facto de essa narrativa ser apresentada numa língua originária do continente europeu constitui, desde logo, um indicador da indissociabilidade do labor literário de Achebe à colonização da Nigéria de onde o autor é originário.

Essa constatação impele-nos a uma referência ao processo de "centralização" da Nigéria, sendo o termo centralização aqui usado, metaforicamente, para referir as transformações operadas no seio das sociedades africanas, em geral, e da igbo, em particular, em decorrência das políticas ditadas pelo poder colonial. Essas políticas marcaram sobremaneira a produção e a divulgação do discurso histórico, ficando o mesmo visivelmente acoplado à visão ocidentalizada sobre espaços onde o colonialismo aportou. Assim, a noção de "a-historicidade", aliada à ideia de inferioridade civilizacional e cultural dos povos colonizados, converteu-se numa das marcas indeléveis do processo de "centralização".

É, precisamente, no quadro dessa hierarquia, gerada pela colonização, que conduziremos a leitura da obra Quando Tudo Se Desmorona (2008 [1958]), de Achebe. Para tal, partimos de uma perspetiva teórica subjacente à crítica pós-colonial e ao quadro do romance carnavalesco e polifónico de Mikhail Bakhtin. Pretendemos evidenciar a riqueza histórico-cultural patente no nosso corpus e o papel da memória como fonte do conhecimento histórico e a sua relevância para a conceção de um discurso alternativo aos cânones ocidentais por via da literatura. Constitui também nossa intenção ressaltar os pontos de confluência entre os substratos teóricos que sustentam a nossa análise. 


\section{A dimensão ideológica do discurso histórico no contexto (pós) colonial}

Começamos a nossa abordagem pelo campo da produção do discurso histórico no quadro da dicotomia centro-periferia resultante da cartografia colonial, lembrando, para o efeito, Edward Said (1983 [1975]), que sublinha o facto de os textos serem institucionalizados pelas culturas reinantes como resultado de alguns custos humanos. A título de exemplo, assinalamos os textos escritos a partir de uma perspetiva colonial que, ao serviço das culturas dominantes, revela(r)am uma "miopia seletiva" no exercício de registo e divulgação das realizações das culturas dominadas/colonizadas, havendo, por este facto, a necessidade de se alterar esse quadro seletivo.

No campo da história, por exemplo, a inclusão das perspetivas específicas dos emudecidos implica a realização de um complexo esforço para a erradicação da monoglossia patente no discurso histórico sobre o colonialismo produzido pelo ocidente. Esse esforço passa pela crítica epistemológica dos termos e contextos da produção do conhecimento histórico, pela desnaturalização dos significados e referências cognitivas, pela inclusão dialógica dos impensados e das experiências dos colonialismos, como sublinham Catarina Gomes e Paula Meneses (2011). Para Gomes e Meneses (idem, ibidem), o facto de as histórias coloniais revelarem uma incompletude cultural transforma-as em locais de excelência para a prática de um exercício de hermenêutica diatópica dos factos históricos, do qual resultará, necessariamente, um diálogo entre as culturas centrais e periféricas. No campo da história, este exercício de interculturalidade converte-se, no dizer dessas autoras, num exercício de inter-historicidade.

Analisando a produção de textos, em geral, importa reconhecer que cada texto constitui uma ocasião de afirmação de vozes e está localizado num contexto específico que, por seu turno, é parte integrante de um contexto mundial, ou cosmopolita, como refere Said (1983 [1975]: 39). Esses fatores obrigam a que a análise de cada texto seja concebida à luz das suas circunstâncias específicas. A partir dessa necessária conexão, o texto é tido como um evento detentor de particularismos históricos. Isto significa que, no quadro de um ambiente global, cada texto detém uma situação específica, devendo a crítica literária prestar atenção ao ambiente sociocultural a partir do qual o mesmo é lido e/ ou concebido (idem: 35). Assim, para os escritores e críticos pós-coloniais, essa indispensável atenção constitui um fator crucial para a localização, evocação e afirmação do seu espaço geográfico, assim como para a apresentação da sua liminaridade, sendo estas marcas fundamentais da sua presença, intervenção e permanência no mundo (Ashcroft e Ahluwalia, 2001: 21-22).

A leitura crítica dos textos ao abrigo do binário "filiação e afiliação", como já referimos, ilumina a possibilidade de olhares críticos diferenciados. Uma vez que o conceito de filiação está ligado à divisão da sociedade entre centro e periferia e vinculado a processos de identificação cultural, Said (1983 
[1975]: 35) promove o conceito de afiliação como um princípio orientador da crítica humanista visando estimular abordagens plurais sobre o texto literário e libertar o crítico de análises assentes numa estreita relação de "filiação" dos textos não ocidentais aos seus congéneres ocidentais, dominantes. Para Said (idem, ibidem), a afiliação permite ver o texto como um fenómeno do mundo, localizado, de modo transversal, numa teia de desconexões não literárias, não canónicas e não tradicionais, libertando, assim, a crítica da visão ancorada no cânone europeu, factos que, na nossa perspetiva, permitem a audição plena das vozes localizadas em contextos não ocidentais.

Porém, a transposição das vozes locais para o universo literário decorre de um exercício de revisitação de factos histórico-sociais. Assim, a memória desempenha um papel preponderante ao servir como ferramenta para a recuperação, transmissão e preservação de legados, abrindo-se, por via desse tríplice exercício, a possibilidade de (re)construção de textos alternativos, ancorados numa perspetiva de inclusão dialógica das vozes das culturas ditas marginais. Ou seja, esse exercício de revisitação permite a eclosão de contradiscursos promotores da ideia de transculturalidade, sendo esta uma característica marcante das atuais identidades culturais, fundamentalmente as não-ocidentais. Entendemos, por este facto, ser relevante efetuar uma breve abordagem à questão da identidade e ao papel da memória social na edificação das identidades culturais.

\section{A memória social e a construção da identidade cultural}

Referindo-nos, agora, à questão da identidade cultural, importa frisar que a mesma constitui um domínio cuja delimitação a um único campo do saber científico se afigura difícil pelo facto de estar intimamente ligada ao estudo da memória social, um domínio cujas abordagens percorrem, por seu turno, distintas áreas científicas.

De um modo geral, a identidade cultural coletiva pode ser definida como a via pela qual uma comunidade se demarca de outras, partindo do delineamento de caracteres próprios, que vão desde as línguas às manifestações culturais, passando pela história dessa comunidade. Os núcleos gestacionais da identidade coletiva localizam-se num passado comum e a mesma vai sendo consolidada ao longo de várias fases da construção de uma determinada sociedade. A identidade cultural coletiva aliada à nação implica um sentimento de pertença a uma nação e pressupõe a partilha de referências a um passado comum, a uma memória e à crença de que o seu coletivo detém características próprias, ou seja, uma identidade, podendo esta ser aferida em distintos níveis 
(Sobral: 2006, 2) ${ }^{1}$, como, por exemplo, a um nível nacional, estando ancorada a uma memória social cuja definição, por seu turno, emana de uma conceção sociológica da memória, proposta por Maurice Halbwachs². Halbwachs (1992 [1925]: 14) considera a memória como um facto social porquanto a edificação da mesma pressupõe a existência de uma relação de partilha cultural no seio de um determinado grupo social. A memória social, opina Halbwachs (idem: 36), constitui uma reconstrução e uma representação do passado elaborada no presente, tendo como base depoimentos de testemunhas ou de partícipes de factos que ocupam lugar na memória de uma nação.

Halbwachs (idem, ibidem) sublinha que qualquer lembrança, ainda que pessoal, se encontra relacionada com um conjunto de noções ligadas à vida material e moral das sociedades. Esta perspetiva enfatiza a dimensão social da memória, sem, contudo, esquecer a sua vertente individual (Halbwachs, 1992 [1925]: 15). Embora existam outras conceções da memória ${ }^{3}$, todas elas acabam por ligá-la a um espaço de partilha que nos conduz a um sentimento de pertença a um grupo social (Sobral, 2006: 3). Como sublinha Halbwachs (1992 [1925]: 37), a memória individual tem necessidade de apelar a lembranças do nosso grupo social de pertença, reportando-se a pontos de referência fixados pela sociedade.

Elsa Peralta (2007: 6), alinhando no diapasão de Halbwachs, lembra que é na sociedade que os indivíduos adquirem as suas memórias, ficando, assim, as memórias individuais sujeitas aos padrões coletivos. Isto ocorre porque, como diz Peralta (idem, ibidem), em última análise, o que recordamos, enquanto indivíduos, é sempre condicionado pelo facto de pertencermos a um grupo. No entanto, convém ressaltar que a sujeição da memória a determinismos sociais não implica negligenciar as tensões dialéticas entre a memória individual e a construção social do passado, daí que o indivíduo não possa ser considerado uma espécie de "autómato" passivamente obediente à vontade coletiva (idem, ibidem.).

Em suma, pertencemos a comunidades mnemónicas, podendo estas ser de âmbito micro e macrossocial (família e nação, respetivamente). Enquanto seres sociais, possuímos uma identidade social que se ramifica em distintos campos (classe, género, ocupacional, etc.), sendo a identidade nacional uma delas, que

1 Usando o exemplo europeu, Sobral considera que podemos falar de uma identidade supranacional, ligada à União Europeia (U.E.), e de uma identidade nacional. Sobral (Sobral: 2006, 3) sublinha que o sentimento de pertença à Europa se manifesta, sobretudo, em termos institucionais, ligados ao presente, enquanto a ligação à nação ocorre por via da memória social, com enfoque ao passado, à história e a dimensões culturais ou a uma identidade coletiva, que conduz a Nós.

2 Pelo facto de recordar constituir um ato eminentemente individual, durante muito tempo, a base social da memória foi negligenciada. Só recentemente as ciências sociais passaram a dedicar uma maior atenção a esta matéria, sendo de atribuir a Halbwachs a inauguração da abordagem sobre a memória como fenómeno eminentemente coletivo, colocando-a, assim, na agenda das ciências sociais (Peralta, 2007: 5).

3 Como, por exemplo, a psicológica, a paleontológica e a neurocientista. Vide Sobral (2006: 3-4) para uma leitura detalhada. 
se resume no Nós e na constatação da nossa diferença relativamente a outros, tal como afirma José Manuel Sobral (2006: 10). O autor acentua também as implicações que a globalização aporta ao conceito de identidade, atendendo à troca de valores culturais e à profusão de diásporas (idem: 1) e, por consequência, a e/imigração de traços identitários.

Os argumentos epigrafados relativos à memória, nomeadamente o seu papel na formação da identidade coletiva, a sua relação com um espaço de pertença e de partilha de valores, assim como a um passado histórico, permitem-nos falar em identidades coletivas transculturais. Esta aceção do conceito pode ser entendida como aquela identidade resultante de ligações contínuas de contaminação que distintas culturas tece $(\mathrm{ra}) \mathrm{m}$ em consequência de vários fenómenos sociais, como, por exemplo, a expansão europeia e o colonialismo, que viriam a ditar os atuais mosaicos geográficos e socioculturais africanos, por exemplo, fortemente marcadas por uma transculturalidade.

$\mathrm{O}$ conceito de transculturalidade surge face à inadequação dos seus congéneres multi e interculturalidade para a descrição da fisionomia cultural das sociedades atuais pelo facto de ambos encararem as culturas como "ilhas", como territórios fisicamente demarcados por rígidas fronteiras naturais (Welsch, 1999: 194-195). Ao partir do pressuposto da delimitação territorial das culturas, os conceitos de multi e interculturalidade, embora dotados de uma conotação mais positiva relativamente ao conceito tradicional de cultura por admitirem a interação entre culturas, revelaram-se inadequados à descrição da atual situação sociocultural. Decorre dessa afirmação o facto de quer o conceito de multi, quer o de interculturalidade ignorarem o processo de transculturação ${ }^{4}$ que ocorre nas sociedades modernas dada a multitude de culturas que as mesmas congregam, como já referimos. Logo, o conceito de transculturalidade $^{5}$ surge, segundo Welsch (idem, ibidem), para articular a nova realidade cultural resultante da colonização e da globalização, que engloba vários estilos de vida e culturas que se interpenetram ou emergem uma da outra.

Como afirma Said (cit. in Huggan, 2001: 9), deve ser colocado o foco no hibridismo da cultura (...) patente nas novas configurações do mapa cultural.

\footnotetext{
4 A transculturação refere-se à influência cultural recíproca observada nos modos de representação e práticas culturais que ocorrem em "zonas de contacto", que são espaços sociais onde distintas culturas se encontram, colidem, geralmente por via de relações assimétricas de domínio e subordinação, tal como diz Mary Louise Pratt (cit. in Ashcroft, Griffiths e Tiffin, 2004: 233). O termo foi proposto em substituição dos termos aculturação e desculturação, por estes descreverem, de forma redutora, as trocas culturais, enfatizando o sentido centro- periferia dessas trocas e ignorando, portanto, a possibilidade da reciprocidade das influências, ainda que desequilibrada
}

5 A transculturalidade repercute-se a nível macro e micro. O primeiro nível está associado à complexidade e à extrema interconexão observável entre as culturas e constitui uma característica fundamental das sociedades atuais, decorrente dos processos migratórios e das facilidades proporcionadas pelos sistemas mundiais de comunicação. O nível micro reflete-se no indivíduo, uma vez que a realidade associada ao nível macro altera também a formação cultural do indivíduo, que se torna, genericamente, híbrido (Welsch, 1999: 196-197) 
Esta perspetiva, argumenta Graham Huggan (2001: 9), proporciona solidariedades transnacionais na era da fragmentação cultural e da dispersão de pessoas, bens e ideias.

Embora a transculturalidade não seja uma realidade recente, uma vez que ela começa, na verdade, com a conquista dos novos mundos, o conceito vem dar resposta à necessidade de se efetuar uma leitura adequada do(s) contexto(s) sociocultural(is) dos nossos dias e das suas ligações ao passado histórico. Esta constatação sanciona, em nossa opinião, a relação entre os conceitos de transculturalidade e inter-historicidade, estando estes conexos a uma memória social.

Em síntese, entendemos a identidade coletiva transcultural como aquela que se funda no reconhecimento das influências mútuas, que se realiza(ra)m entre as culturas, resultando numa interpenetração cultural, ainda que, por vezes, desproporcional e, por isto, geradora de alguma tensão, também ela objeto de registo por parte da memória. No quadro da dinâmica cultural acima descrita, emergem várias dissonâncias, cada uma delas evidenciando ações conducentes à promulgação de discursos que chamam a atenção para formas explícitas ou dissimuladas de discriminação, constituindo, assim, alertas sobre a eclosão de novos modelos de colonização.

É, precisamente, dentro do quadro de um mútuo reconhecimento entre as distintas culturas que o pensamento crítico de Bakhtin, nomeadamente através dos conceitos de carnavalização e de dialogismo, assim como da sua conce-

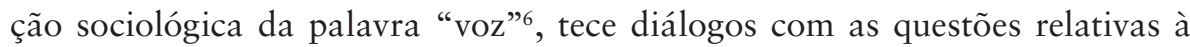
memória social e ao conceito de transculturalidade. Em geral, esses conceitos bakhtinianos, por um lado, repudiam o silenciamento; por outro, enaltecem a importância da capacidade de conhecimento do Outro através da observância da sua vez e do respeito pela sua "voz". O ponto de convergência desses conceitos situa-se na ideia do contacto livre e familiar entre pessoas e o "diálogo de vozes". Como refere Bakhtin (1984: 123), o contacto livre entre pessoas permite a interação de diferentes culturas e distintos estratos sociais que se encontram na arena do carnaval, sendo esta o símbolo da performance comum"7. Para Bakhtin (1998: 263), essa amálgama de atores concorre para a existência de uma diversidade de discursos, ou seja, um dialogismo ou heteroglossia, que se converte em polifonia, quando é transposto para o universo literário. A configuração da heteroglossia fora do universo literário, por exemplo, ao nível da produção e divulgação do conhecimento histórico implica, necessariamente, leituras críticas plurais, despojadas de noções filiadas numa matriz

6 Bakhtin usa a palavra "voz" de modo especial, relacionando-a não apenas com aspetos linguísticos, mas também com questões de natureza social. Para Bakhtin (1998: 332), o vocábulo "voz" está também conexo à ideologia, poder, grupos sociais e à necessidade da sua representação.

7 Além do contacto livre e familiar, outro aspeto conexo ao conceito bakhtiniano de carnaval é o seu principal ato, a coroação do rei ou da rainha do carnaval, como resultado da destronização dos seus predecessores, funcionando como uma metáfora da renovação. Vide Bakhtin (1984: 123-124). 
reducionista e centralizadora do pensamento crítico, isto é, leituras minuciosas das componentes dos contradiscursos presentes nos textos que reagem à dimensão colonizadora dos discursos nos mais distintos campos, sendo essa a premissa que preside a análise da obra de Achebe que seguidamente efetuamos.

\section{A narrativa achebiana no contexto da inter-historicidade pós-colonial}

Consagramos os próximos parágrafos à análise crítica de Quando Tudo Se Desmorona, de Chinua Achebe (2008 [1958]), à luz da abordagem efetuada. $\mathrm{O}$ romance de Achebe tem como temas estruturais a realidade resultante do contacto entre as civilizações igbo e inglesa. Ao longo da obra, a história da comunidade igbo é recuperada através da trajetória de Okonkwo, a personagem principal da trama, que luta para preservar a coesão dos igbo, visando mantê-los isentos da "contaminação" e da subjugação britânica. Assim, comparecem também no discurso narrativo os conquistadores, alheios ao ambiente sociocultural local. A temática convocada para a obra, elaborada por via de uma narrativa ancorada numa hibridação discursiva, própria da literatura carnavalizada e pós-colonial, descreve as realidades pré e pós-colonial específicas da comunidade igbo. Assim, as "vozes" e o tempo são inter-relacionados de modo a produzir um quadro alegórico do "encontro" colonial.

O capítulo inaugural anuncia o ambiente carnavalesco do romance através da coroação de Okonkwo, aos dezoito anos, antecedida da destronização de Amalinze, como resultado da sua derrota após sete anos de invencibilidade quebrados por Okonkwo. Assistia-se, assim, a uma renovação. Como refere Bakhtin (1984: 125), o ritual da entronização e destronização expressa a inevitabilidade da mudança e, simultaneamente, o poder criativo da renovação, assim como a contingência de todas as estruturas, autoridades e hierarquias. No caso de Quando Tudo Se Desmorona, a ascensão de Okonkwo representa a renovação da comunidade igbo no período anterior à presença inglesa. No entanto, outras categorias associadas à lógica do carnaval e ao romance carnavalesco, por exemplo, o contacto livre e familiar entre atores pertencentes a diferentes categorias sociais (mesalliances $)^{8}$, são apresentadas à medida que o enredo se desenvolve. Nessa conformidade, é possível observar a união entre jovens e idosos, entre a alta e a baixa sociedade conectadas em típicas mesalliances (juntos, os polos opostos trabalhavam para a manutenção das normas inerentes à civilização igbo e à preservação da sua identidade). Convém referir que as alianças entre opostos são reforçadas pelo facto de, em muitas ocasiões, as mesmas ocorrerem na "ilo", a praça central de Umuofia, a capital dos igbo. Em termos comparativos, a "ilo" corresponde à praça carnavalesca, o ponto de encontro de todas as classes e símbolo da performance comum, ou seja, a arena 
do carnaval, a carnival square 9 de que nos fala Bakhtin. Como resultado desse amalgamento, o sagrado e o profano coabitam, confirmando, assim, a união dos opostos em Umuofia.

$\mathrm{Na}$ sua qualidade de "rei" e de entidade unificadora de Umuofia, as ações de Okonkwo eram legitimadas pelo direito costumeiro e pelas crenças que regulavam a vida da comunidade igbo. Tal como o direito positivo, o direito costumeiro contém proibições e punições, tendo estas punições conduzido Okonkwo à primeira fase da sua destronização e consequente exílio em Mbata após ter assassinado um rapaz. Essa punição é acompanhada por uma profanação simbólica, marcada pela destruição dos seus pertences e pela queima da sua casa como meio de purificação de Umuofia, ao abrigo das leis locais. Tais atos remetem, uma vez mais, para a nossa leitura ao pensamento de Bakhtin (1984), que alude à presença do fogo como elemento associado ao carnaval, fundamentalmente no que diz respeito à sua natureza ambivalente, ou seja, o seu poder de destruição e a possibilidade de renovação engendrada por esse mesmo poder destrutivo. Com o exílio de Okonkwo, consuma-se a presença europeia em Umuofia. O desembarque de missionários ingleses em Umuofia forçou a abertura de espaços no mosaico dos hábitos locais, ocorrendo, assim, as primeiras etapas da contaminação cultural de Umuofia e da construção de uma realidade transcultural, silenciadora da identidade do povo igbo e, por esse facto, desequilibrada. De algum modo, essa realidade constituía, na verdade, os alicerces sobre os quais se veio a erguer o processo de globalização ${ }^{10}$ dos espaços de aportamento das "missões civilizadoras". Como sublinham Ashcroft, Griffiths e Tiffin (2004: 110),

A globalização é o processo pelo qual indivíduos e comunidades locais são afectados por forças económicas e culturais que operam a nível mundial. De facto, é o processo de transformação do mundo numa aldeia global (...). Ela reflete uma mudança na organização das relações sociais, uma vez os indivíduos e as comunidades têm acesso ao conhecimento e às culturas globalmente disseminadas.

A citação anterior dá-nos a sensação de estar perante um processo inócuo. Porém, recordam Ashcroft, Griffiths e Tiffin (idem; ibidem), a globalização envolve muitos fatores aos quais são inerentes distintas questões, das quais

9 A praça pública é o símbolo da performance comum. A arena central só pode ser a praça pública uma vez que a ideia central subjacente ao carnaval é a de que o mesmo é universal e todos dele devem participar por via de contactos "familiares" (Bakhtin, 1984: 128).

10 Embora o termo tivesse ascensão meteórica a partir de meados da década de 80 do século passado, o processo, como tal, começa com a "descoberta dos novos mundos", ou seja, no século XV, com a expansão europeia. O século XV constituiu o ponto de partida, uma vez que o mundo começa, nessa altura, a ser afetado por forças económicas e culturais que operavam à escala planetária, mais especificamente as forças europeias. Na verdade, a diferença, hoje, reside na presença de novos atores (E.U.A., China, por exemplo) e de outros fatores como as diásporas, as Tecnologias de Informação e Comunicação e os media, que vieram facilitar ou acelerar o processo. 
salientamos aquelas ligadas a aspetos antropológicos e à configuração dos espaços territoriais, que, por sua vez, trazem à tona o conceito de imperialismo ecológico porquanto este descreve o modo como as sociedades colonizadas foram fisicamente transformadas pela experiência da ocupação colonial.

Assim, através da arte literária, Achebe descreve, de forma dramática, a fenda que se gerou no (sub)solo que sustentava os pilares da comunidade igbo nos primeiros momentos da sua ocidentalização, ou seja, da sua "centralização". Para tal, o autor rebusca capítulos da história silenciados pela historiografia colonial e coloca ao dispor dos seus leitores uma versão "desmascarada" desses capítulos narrada pela voz do "invadido", assumindo e enumerando também as debilidades dos igbo, quando revela, por exemplo, a "permissão" dada aos ingleses para procederem à ocupação da "igbolândia". Podemos observar no romance que há uma culpa partilhada relativamente à situação sociocultural desenvolvida em Umuofia após a chegada dos ingleses, pois, como afirma Obierika (in Achebe, 2008 (1958): 152-153),

Os nossos homens e filhos juntaram-se às fileiras dos estranhos. Juntaram-se a esta religião e ajudam a sustentar este governo (...). O homem branco é muito esperto. Chegou calma e pacificamente com a sua religião. Divertimo-nos com os seus disparates e permitimos que ficasse. Agora conquistou os nossos irmãos e o nosso clã já não pode agir como um. Apontou uma faca ao que nos mantinha unidos e nós desmoronámos.

A transcrição anterior reproduz o lamento pelo resultado do confronto entre as culturas igbo e inglesa, nomeadamente, a quebra dos alicerces que sustentavam a comunidade igbo e a construção forçada de um novo espaço transcultural, "partilhado" por invasores e invadidos, durante os sete anos de exílio de Okonkwo em Mbata e nos anos subsequentes. O regresso de Okonkwo à Umuofia representa a segunda etapa da sua destronização. A sua ausência resultou na influência marcante da presença dos missionários que, como já afirmámos, operaram visíveis mudanças nos costumes locais das quais resultaram alterações da paisagem sociocultural de Umuofia. A vitória do modelo europeu provocou um conflito permanente de aceitação e rejeição, por exemplo, ao nível religioso, tal como sugere o diálogo que a seguir transcrevemos:

Dizes que há um Deus supremo que fez o céu e a terra - Disse Akuna. Também acreditamos Nele e chamamos-Lhe Chukwu. Foi ele quem fez todo o mundo e os outros deuses.

Não existem outros deuses - disse o Sr. Brown. - Chukwu é o único deus e todos os outros são falsos" (in Achebe, 2008 (1958): 155-156). 
Ao inserir as vozes da memória social local, Achebe liberta, de forma metafórica, a sociedade igbo da visão marcada pela miopia seletiva da historiografia ocidental, ou seja, da visão parcial da história que oculta(va) a riqueza da estrutura do tecido sociocultural dos povos não ocidentais. Ao incorporar essa riqueza, feita, sobretudo, através das marcas linguísticas locais, da exaltação da matriz sociocultural igbo e por via da estrutura do romance centrada na figura de Okonkwo, o herói igbo, Achebe põe em evidência a possibilidade de os elementos identitários igbo constituírem, tal como os seus congéneres europeus, matéria-prima para a conceção do texto literário. No dizer de Pires Laranjeira (2008: 183), a história de Okonkwo, o herói da tribo marginalizada, não podendo ser escutada no capítulo da história ocidental, foi retirada aos igbo por Achebe e, ao colocá-la no seu romance, este tornou-a universal.

Por conseguinte, entender Quando Tudo Se Desmorona implica escrutinar, ao abrigo de uma hermenêutica diatópica dos factos históricos, os elementos estruturantes do contradiscurso patente no romance. Isto pressupõe uma "desfiliação" do texto relativamente às matrizes do centro e a consequente localização do mesmo no espaço metonímico onde se situa o imaginário "achebiano". Essa "desfiliação" deverá ser tida como o ponto de partida para a projeção do texto para um macro-universo, do qual, com as suas peculiaridades histórico-culturais, também dele faz parte por direito. Desta forma, a narrativa constitui uma zona de contacto entre a periferia e o centro, promotora de um ambiente dialógico no qual as línguas e culturas representativas desses espaços partilham a mesma plataforma. Ao promover o encontro de vozes e de línguas, Achebe projeta a ligação do texto a um contexto sociocultural determinado, ao mesmo tempo que difunde a sua matriz (trans)cultural para uma rede global de leitores. A oposição direta entre elementos identitários, como, por exemplo, as culturas e as línguas, pode ser lida como uma das formas de remoção das não ocidentais da posição periférica que lhes foi atribuída, colocando-as, assim, em paralelo com as suas homólogas europeias. No entanto, Ngungi Wa Thiong'o, a partir de uma perspetiva diacrónica, ressalta as distintas funções das línguas europeias, a nível do continente africano. Na óptica de Thiong’o (2006 [1986]: 19),

O inglês, o francês e o português tornaram-se as línguas através das quais os africanos apresentaram as suas frentes nacionalistas contra os seus opressores. Após as independências essas línguas continuam a funcionar como fatores de união. Contudo, Achebe lembra ao seus leitores que a língua inglesa será capaz de carregar o peso da experiência africana. Mas terá de ser uma 'nova' língua inglesa que, embora permaneça ligada a sua terra ancestral, é no entanto alterada para estar em consonância com a realidade dos seus novos contextos africanos. 
Nessa conformidade, Achebe põe ao dispor dos seus leitores uma escrita subversiva que, no dizer de Inocência Mata (2008: 111),

Vai minando a língua inglesa na sua ontologia etnocêntrica, disseminando nela a cultura igbo, através da utilização de recursos linguísticos pertencentes ao vocabulário da mesma e da exaltação da sabedoria popular oral, expressa em provérbios que pontuam as falas das suas personagens.

Ainda a respeito da coabitação lexical (anglo-igbo), Harry Garuba (2009: 248-249) enfatiza que, embora essa coabitação permita a inclusão de uma matriz africana, o maior foco do trabalho criativo de Achebe reside no modo como o autor se apropria dos recursos da oralidade, expandindo-os e reconfigurando-os, transformando-os, deste modo, em artefactos literários. No dizer de Garuba (idem, ibidem), mais do que uma mera reflexão acerca do paradigma da oralidade, o ponto conceptual almejado por Achebe consiste num processo de mediação, transformação ou de sedimentação do repertório da oralidade, sendo este o elemento caracterizador da relação entre o autor e a sua tradição oral.

Mala Pandurang (2009: 347) admite que, embora tivesse predecessores como The Palm Wine Drinkard (1953) ${ }^{11}$, escrito por Amos Tutuola, Quando Tudo se Desmorona (1958), de Achebe, foi a primeira obra a ser aclamada internacionalmente, inspirando uma primeira geração inteira de escritores africanos a apropriarem-se da língua inglesa, incorporando nela, com fins políticos, técnicas de oratura e conjuntos lexicais africanos, demonstrando a sua mestria na "africanização" da língua colonial. Esta tipologia de escrita estava alicerçada numa urgência de afirmação e de recuperação identitária em distintas partes do continente africano face à severa negação da psique humana da África Negra (idem, ibidem). A presença da língua inglesa no seio dos igbo pode, na nossa perspetiva, funcionar como uma metáfora que alude à viagem por eles operada em direção ao modelo britânico, um percurso fortemente recusado por Okonkwo. Okonkwo expressa o seu inconformismo pelo facto de o seu povo se ter resignado à nova realidade e não ter lutado pela sua terra e pelas suas crenças, fazendo-o de uma forma trágica, cometendo o suicídio. Ao optar por essa via, Okonkwo acabou por violar as leis igbo e, por esse facto, não foi merecedor de um funeral a preceito e nem podia ser sepultado por nativos de Umuofia. Assim sendo, paradoxalmente, apenas aqueles que ele tentou combater estavam "legalmente" habilitados a fazer o seu funeral. Como podemos ler no romance:

11 O Bebedor de Vinho de Palmeira (traduzido para português em Lisboa, pelas Edições 70, em 1980, para a coleção Vozes de África do INALD, e, em São Paulo, pelo Círculo do Livro, em 1970, com o mesmo título. 
Aquele era um dos homens mais valorosos de Umuofia. Vocês levaram-no ao suicídio e agora será enterrado como um cão, disse Obierika.

É um ato impensável um homem pôr fim à sua vida. É uma ofensa à terra e o homem que o pratica não será enterrado pelos membros do seu clã. O seu corpo é maligno e apenas estranhos the podem tocar (in Achebe, 2008 (1958): 176).

Assim, ao descrever a trajetória do herói igbo, a natureza dos conflitos sociais e psicológicos desenvolvidos em Umuofia, durante os períodos pré e pós-colonial, Achebe convoca a memória ostracizada pela história resultante da visão autorizada pelo centro, para a reelaboração de uma (inter)historicidade abrangente, a partir de um exercício de reescrita da história, baseado numa hermenêutica diatópica e dialógica dos factos históricos, evocando, para o efeito, marcos da identidade igbo. A obra articula conflitos subjetivos e aspirações coletivas num sincretismo dialógico que reproduz as vozes e falas de todos os ocupantes do ambiente carnavalesco e transcultural do romance, dando ao leitor notas marcantes do espaço de pertença da obra ou, se preferirmos, da sua mundanidade, usando um conceito de Said (1975 [1983]).

\section{Conclusão}

A leitura do romance de Achebe, feita a partir de uma perspetiva crítica pós-colonial induz-nos a uma reflexão em torno do papel da literatura na produção de alternativas ao discurso "oficial" do centro, pois, como nos recorda Huggan (2001: 40), a literatura africana, tal como outras pós-coloniais, é, em termos genéricos, portadora de uma dimensão, simultaneamente, recuperadora e desconstrutora da identidade cultural e das expectativas ocidentais, respetivamente. Para tal, ela trabalha no sentido do desmantelamento das formas que privilegiam a supremacia do mundo ocidental. Obras como Quando Tudo se Desmorona funcionam, de certo modo, como contradiscursos, ou se preferimos, como contranarrativas etnográficas que elaboram o escrutínio dos questionáveis axiomas subjacentes às descrições antropológicas do ocidente, relativamente às culturas não ocidentais (idem: 41). Para o efeito, no seu romance, Achebe procede à re-leitura dos textos da história, revelando ligações entre os mesmos e o processo colonial, numa ótica "marginal", diferenciada daquela produzida a partir do centro, prestando, como diz Thomas Bonnici (2005), atenção às lacunas, às ironias e aos silêncios, bem como às metáforas do texto canónico. De facto, Achebe efetua uma releitura do texto canónico a partir do rastreio e da audição de várias histórias, fundamentalmente aquelas colocadas à margem da biblioteca oficial (Mata, 2012: 39). Assim, ao serem exercitadas pelo autor, a re-leitura e a re-escrita da história permitem a eclosão de um novo texto que problematiza e questiona o texto da biblioteca oficial. Por este facto, partilhamos a perspetiva de Mata (2012: 39-40) quando considera que 
a literatura equivale também a um registo histórico, onde o pré-colonial funciona como lugar da memória e as cicatrizes da colonização, a nível cultural, como pedra angular da re-construção identitária.

Em resumo, recorrendo ao labor literário, Achebe reabilita a história silenciada, concebendo um discurso que, do ponto de vista temático-lexical, se afasta das propostas ocidentais relativas ao registo e à divulgação de factos históricos, lembrando aos seus leitores que, não obstante as alterações profundas ocorridas na idiossincrasia igbo e o ostracismo a que foi relegada, a história dos núcleos fundacionais dos igbo subsiste viva na memória coletiva dessa comunidade.

A terminar, diríamos que o romance Quando Tudo Se Desmorona constitui um exercício pleno de reescrita da história, sendo, portanto, de considerar o romance como um contributo à efetivação da inter-histocidade pelo facto de representar um pungente retrato literário de parte da história africana. O romance de Achebe aqui analisado convida-nos à reflexão sobre a natureza do recontro colonial e remete-nos para uma atmosfera que, dados os estereótipos construídos pela história e o contradiscurso produzido em resposta à versão ocidentalizada da história, nos diz que o futuro jamais será igual ao passado.

\section{Referências bibliográficas}

ACHEBE, Chinua (2008 [1958]), Quando Tudo Se Desmorona, Luanda, Instituto Angolano do Livro e do Disco.

ASHCROFT, Bill, AHLUWALIA, Pal (2001), Edward Said, London and New York, Routledge. ASHCROFT, Bill, GRIFFITHS, Gareth, TIFFIN, Helen (2004 [1998]) (orgs.), The Post Colonial Studies Key Concepts, London and New York, Routledge.

BAKHTIN, Mikhail (1984 [1963]), Problems of Dostoevsky's Poetics, History and Theory of Literature, vol. 8., Manchester, Manchester University Press.

BAKHTIN, Mikhail (1998 [1981]), The Dialogic Imagination, Texas,The University of Texas Press.

BONNICI, Thomas (2005), "Avanços e Ambiguidades do Pós-colonialismo no Limiar do Século 21”, Légua \& Meia: Revista de Literatura e Diversidade Cultural, 4 (3), pp. 186-202 [Online], disponível em: http://www2.uefs.br/leguaemeia/3/3_186-202_avancos.pdf [consultado em: 09/04/2017].

GARRUBA, Harry (2009), “The Critical Reception of African Novel”, in F. I. Abiola (org.), The Cambridge Companion to the African Novel, Cambridge and New York, Cambridge University Press, pp. 243-262.

GOMES, Catarina, MENESES, Maria Paula (2011), "História e Colonialismo: Por uma InterHistoricidade", Recueil Alexandries [Online], disponível em: www.reseau-terra.eu/article1223.html [consultado em: 12/04/2017].

HALBWACHS, Maurice (1992 [1950]), A Memória Colectiva, São Paulo, Edições Vértice/ Editora Revista dos Tribunais.

HUGGAN, Graham (2001), The Post-Colonial Exotic: Marketing the margins, London and New York, Routledge. 
LARANJEIRA, Pires (2008), “Things Fall Apart: A mudança no mundo igbo”, in D. Burness, I. Mata e V. Hartnack (orgs.), When Things Came Together: Studies on Chinua Achebe, Lisboa, Faculdade de Letras da Universidade de Lisboa, pp. 174-183.

MATA, Inocência (2008), "O Problema de Umuofia", in D. Burness, I. Mata e V. Hartnack (orgs.), When Things Came Togheder: Studies on Chinua Achebe, Lisboa, Faculdade de Letras da Universidade de Lisboa, pp. 103-133.

MATA, Inocência (2012), "Memória da Colonização e a Sentença do Futuro na Figuração da Nação: de Castro Soromenho a Leonel Cosme e Pepetela", in A. M. Leite, H. Owen, R. Chaves e L. Apa (orgs.), Nação e Narrativa Pós- Colonial: Angola e Moçambique, Ensaios, Vol. I, Lisboa, Edições Colibri, pp. 37-56.

PANDURANG, Mala (2009), "Chinua Achebe and African Experience: A socio-literary perspective”, in F. I. Abiola (ed.), A Norton Critical Edition: Chinua Achebe Things Fall Apart - Authoritative Text, Context and Criticism, New York and London, W.W. Norton, pp. 343-358.

PERALTA, Elsa (2007), "Abordagens Teóricas ao Estudo da Memória Social: Resenha Crítica”, Arquivos da Memória: Antropologia, Escala e Memória, 2 (Nova Série), Centro de Estudos de Etnologia Portuguesa, pp. 4-23 [Online], disponível em: www.fcsh.unl.pt/revistas/arquivos-da-memória/ArtPDF/02_Elsa_Peralta[1].pdf consultado em: 10/04/2017].

SAID, Edward (1983 [1975]), The World, The Text and the Critic, Cambridge and Harvard, Harvard University Press.

SOBRAL, José Manuel (2006), "Memória e Identidade Nacional: Considerações de carácter geral e o caso português", Working Papers, WP4-06 [Online], disponível em: http://www. ics.ul.pt/publicacoes/workingpapers/wp2006/wp2006_4.pdf [consultado em: 24/06/2015].

THIONG'O, Ngügï wa (2006 [1986]), Decolonising the Mind: The politics of language in African literature, Nairobi, Oxford and Portsmouth, East African Educational Publishers.

WELSCH, Wolfgang (1999), "Transculturality: The Puzzling of Cultures Today", in M. Featherstone e S. Lash (eds.), Spaces of Culture: City, Nation, World, London, Sage, pp. 194-213. 